\title{
Social Capital in the Health Development of Children
}

\author{
Andreas Klocke ${ }^{1}$ (D) $\cdot$ Sven Stadtmüller $^{1}$
}

Accepted: 8 July 2018 / Published online: 17 July 2018

(C) The Author(s) 2018

\begin{abstract}
Social capital addresses networks and ties, which deliver support, information and trust for the members of these networks. Being a member of such a network is your social capital, which in turn might improve your quality of life. This paper investigates the impact of social capital on the health and health behaviour of children in their growing up process. Therefore, the panel design employed includes 10 to 12year-old school children, followed up for three annual waves. The data used is from the German survey of Health Behaviour and Injuries in School-Age-A Panel Study 20132020 ( $N \approx 10.000$ per wave). We took a longitudinal perspective to estimate the impact of changes in the social capital's volume on health-related variables by relying on fixed effects models. Furthermore, we analysed whether the effect of social capital differs between certain socio-demographic groups, e. g. between children from high- and lowprivileged households. The findings suggested a causal influence of social capital on their health and health behaviour. Intrapersonal changes in social capital significantly affected an individual's health and health behaviour. Moreover, this effect was evenly distributed among all the socio-demographic groups, meaning that all children benefit from an increase in social capital in the same way. This suggested that for the health development of all children and adolescents, it is of foremost importance to build and stimulate social networks and resources (social capital) rather than concentrating solely on the financial aid.
\end{abstract}

Keywords Social capital $\cdot$ Children $\cdot$ Health $\cdot$ Panel data

Andreas Klocke

andreas.klocke@fzdw.de

1 Forschungszentrum Demografischer Wandel (FZDW), Frankfurt University of Applied Sciences, Nibelungenplatz 1, 60318 Frankfurt am Main, Germany 


\section{Introduction}

In an international comparison (between countries) or an analysis of distinguished groups within a given society (within differences), the well-being of populations is high on scientific as well as public awareness (UNDP 2016). Health and health behaviour are the key indicators of a good and satisfying well-being (Veenhoven 2008). How do we accomplish good health and well-being for all groups of people? It is questionable if it is related solely to income or wealth. International rankings show not all wealthy and advanced countries rank at the top of the global league table of happiness (Helliwell et al. 2017). Very often, the Scandinavian countries, the Netherlands or Iceland rank first in this category. These countries show not only a comparatively high level of wealth but also a high level of life expectancy, low corruption and a sense of belonging together, which in turn delivers trust and solidarity. Probably, the degree of inner cohesion and connectedness is also important in this context. Social Capital is the concept that addresses this cohesion. It has been widely used in almost all fields of social research in the recent years (Halpern 2005; Field 2017). This study focuses on the impact of social capital on children's health and health behaviour, with special attention given to the health development in their growing up process. Is there a causal effect of social capital and is it true for all the socio-demographic groups (e.g. family affluence)? To analyse this, we use a panel design of 10 to 12 -year-old school-children and followed them up for three annual waves so far.

In the recent years, many studies have pointed out the close relationship between family background and health behaviour of children. Most often, the link between family's poverty level and health behaviour of children is highlighted (UNICEF 2016). However, in multivariate analyses, a direct connection between family's poverty level and the concrete behavioural pattern in young people is often not found, instead there are intermediate factors like socio-cultural habits at play (Chzhen et al. 2017). These mediators are recorded along with the concepts of risk and protective factors at a young age. Different factors can be delineated here, which are based on the individual (intelligence, self-esteem), the family (family constellation, socio-economic status of the family), the interactive (friends, peer group) or the social (neighbourhood, local commune) circle. These factors' impact on children's behaviour is one of the top contemporary research questions, and is increasingly being discussed under the term 'social capital'. Various studies showed that social capital has a protective effect on the lives of young people (Furstenberg et al. 1999; Halpern 2005; Putnam 2015). Social capital's elements have a positive effect on one's mental as well as physical health (Currie et al. 2012). Halpern (2005: 87) concluded the following literature review: 'Close personal relationships, and intimate, confiding relationships in particular, generally have highly positive impacts on individual mental health, happiness and physical health'. This study's investigation pertains to the question whether social capital affects the young people's health behaviour and the health status over time, using longitudinal panel data rather than crosssectional data.

This study is categorised into six sections. The first section includes social capital's theoretical concept while the second section talks about how it is applicable on children and adolescents. The third section includes the description of the data base. The key variables and an index of social capital in youth is introduced in the fourth section. This 
is followed by the fifth section that includes a section of findings, consisting of the following parts: (i) an analysis of socio-demographic factors that might influence the social capital's volume; (ii) determination of social capital's impact on the health and health behaviour in young people and (iii) the analysis of social capital's significance over time (panel). The sixth section discusses these findings, while the final section points out the study's limitations.

\section{The Theoretical Concept of Social Capital and how it can Be Adapted to Young People}

The concept of social capital became prominent through Putnam's $(1995,2001)$ work, and was first understood primarily in the field of political science regarding shared values and local networks. It was only later that the reference to Bourdieu (1986) was 'rediscovered', and the concept was located at the individual level. Today, there are different understandings of what social capital is (Halpern 2005). Halpern saw social capital at all the three levels of analysis, namely the micro-level (family), the mesolevel (neighbourhood) and the macro-level (nation). Indeed, the concept's frequent use in urban and poverty research is a sign of its accuracy on the micro- and meso-level. On the macro-level, the differences between countries in terms of well-being can be considered an example.

The distinguishing feature of social capital is its focus on the relationships among individuals (Lin 2001). Unlike human capital, which focuses on the individuals' abilities, and economic capital, which measures possession, social capital addresses the networks and ties, in which individuals are woven in. Being a member of a network gives you an advantage, as you gain information, support, access and trust. Through these aspects, social capital can improve one's life satisfaction and well-being. Within these relations, three forms of functioning of social capital can be distinguished (Putnam 2001: 22 f.), which are as follows:

Bonding: Strong direct links between people in a similar socio-demographic and socio-economic or socio-cultural environment.

Bridging: Comparatively weak horizontal connections between different groups, which originate from a similar social class.

Linking: Vertical links between privileged and less privileged groups.

How can the concept of social capital be adapted to the age group of children and young adolescents? Regarding the forms of functioning of social capital, all the three above-mentioned forms can be adapted for different age groups of children and adolescents. Family ties and friendships from socially homogenous groups are not unusual in childhood (bonding).

However, the fellowships found in associations and organisations (e.g. sport clubs, schools) that bring together young people from somewhat heterogeneous family backgrounds are often found in youth (bridging). Perhaps the most difficult are the structures of 'linking', since these structures are hard to establish and might even have a marginalising effect on children from the less advantaged classes because young people very often decipher different social backgrounds. 
However, here we would like to argue for an individualistic approach on the microand meso-level for adapting social capital in youth. In children's everyday life the macro-level of social capital (a just society, social services) will hardly be recognised as such. As Lin (2001) pointed out, the concept of social capital has its starting point on the micro-level and can be extended to the meso- and macro-level as well (see also Bronfenbrenner 1979). The individualistic approach can be captured with Bourdieu's conception of social capital, which is as follows: 'Social capital is the aggregate of the actual or potential resources which are linked to possession of a durable network of more or less institutionalized relationships of mutual acquaintance and recognition' (Bourdieu 1986: 249). In Bourdieu's conception, social capital is only another form of capital in addition to economic and cultural capital (Bourdieu 1986). All three forms of capital are transferable and can be invested and yield 'profit'. They are, thus, embedded in the structure of social inequality. Social capital can moderate (deteriorate or improve) an individual's position in the societal structure of social inequality. It is a multiplier, or when positively applied, functions as a support network. One's economic resources or cultural competencies can have a greater effect in life, if the 'lever' of social capital (connectedness, support) can be applied.

With regard to children and adolescents, the role of general support or 'generalized trust' (Uslaner 2002) is crucial. The possibility of 'profit maximisation' through cooperation or 'strategic trust' (Uslaner 2002) is less relevant in this context. Generalized or moralistic trust '...is a general outlook on human nature...' (Uslaner 2002: 17) and gives children an underlying basic body of trust. Usually children trust their parents independent of their actual (probably disturbing) behaviour. That is generalized trust. We would like to argue, that for children it is not common, to develop strategic trust, where trust is '...primarily based upon personal experiences.' (Uslaner 2002: 17). Rather they trust people as well as institutions (e.g school) in a generalized way. Uslaner addresses the question: Where does moralistic trust come from? His answer: 'Mostly, though hardly exclusively, from our parents. (...) Children respect parental authority and they do also follow parental guidance as a way of expressing their love (...).' (Uslaner 2002: 26). For a good deal this is also true for the school or the neighbourhood, where children develop a general attitude towards these institutions (see measurement of social capital in children).

Support can be expected in crisis situations, which can relate to both emotional and material support. However, in normal everyday life also, the disposition of social capital has a stabilising effect on life. In this analysis, it means an extension from the personal (micro-level) to the meso-level, e.g. the neighbourhood or school (Bronfenbrenner 1979). In this regard, a study conducted by Furstenberg et al. (1999) on socialisation conditions in unfavourable neighbourhoods showed that the variability of behaviour is essentially related to the volume of social capital. As Morrow argued, 'the basic argument, then, is that the extent to which people are embedded within their family relationships, social networks, and communities, and their sense of belonging and civic identity, constitutes 'social capital'. This stock of 'social capital' in turn has an impact on health and wellbeing.' (Morrow 1999: 768). Runyan et al. (1998) found that social capital acts as a buffer in unfavourable social environments. They also showed in the longitudinal data that every element of social capital or the presence of social networks improves the health outcomes of deprived children. 
For children and young adolescents especially, social capital can be described as a trust-based network, which can be accessed when social support is needed. This thought basically relates to Coleman's (1990) work, who defined social capital as something which 'is embodied in the relations among persons' and 'a group whose members manifest trustworthiness and place extensive trust in one another will be able to accomplish much more than a comparable group lacking that trustworthiness and trust'. Anthony Giddens defined trust as the 'confidence in the reliability of a person or system, regarding a given set of outcomes or events, where that confidence expresses a faith in the probity or love of another, or in the correctness of abstract principles' (Giddens 1990: 34). Both the abovementioned quotes underline the importance of generalized trust in relationships between people, which constitutes social capital in general, but is particularly true for children. As children, usually, cannot easily change their personal circumstances, they have to turn to and trust others (often adults) (Putnam 2015). Some scientists (Woolcock 2001: 10) argued that 'trust is better understood not as social capital per se, but rather as a measure of it. We invest in the networks and social institutions that produce trust, not trust in and of itself'. It is hard to distinguish trust either as a core element of social capital or as a pure result of it. If a network or a relation produces trust, it's very likely that we rely on and use this relation because we trust it. So, we would like to regard trust as a core element and function of social capital.

Given the above-mentioned link between social capital and health (behaviour), we expect that children with a high volume of social capital to show a better health status and health behaviour (hypothesis 1). Health in Childhood is to large part determined by emotions of fitness and well-being (Currie et al. 2012; Klocke et al. 2014). Therefore, health indicators should directly gain improvement, when support and general trust account for happiness and a better well-being in children's life. Moreover, children, who gain a higher volume of social capital over time should show a significant better health development (hypothesis 2). If that is true, social capital can be considered a (causal) protective factor in the health development of young people, which should be true for all socio-demographic groups (hypothesis 3).

\section{The Database}

The data base used for this contribution is the panel study 'Health Behaviour and Injuries during School Age', which started on an annual cycle in the school year 2014-15 in Germany. It majorly aims to analyse the causes for injuries occurring at schools. The study initially surveyed the 5 th grade students (10 to 12 -year-olds) and tried to track these children till they reached the 10th grade by surveying them annually.

\footnotetext{
${ }^{1}$ Coleman (1990: 321) also pointed out that unlike economic capital, the 'use' of social capital strengthens and increases social capital and does not 'consume' it. The more I trust (mutual) other people, the more I increase in my social capital. It, thereby, reduces not only control costs but also creates further social capital.
} 


\subsection{Sample Design}

The target population included all the pupils who were enrolled in the 5th grade in the general higher secondary education schools for the academic year 2014-15. As there was no list of these individual children, a selection of schools was made. Within the sampled schools, all the 5th grade classes were surveyed for pragmatic reasons (cluster sampling). A stratified random sample regarding school streaming, ${ }^{2}$ was drawn. The layers in the stratified random sample represented a combination of characteristics, such as the federal state, school stream, school size and urbanity. The gross sample for the first survey included 854 schools in the eleven participating federal states. ${ }^{3}$ Almost onefifth of the schools contacted (17.3\%) participated in the survey (net sample). Compared to the distribution in the sampling frame, the schools that belonged to the highest stream were slightly overrepresented, while there were no differences between the net sample and the sampling frame regarding region, urbanity and school size. On the individual level, we conducted 10,621 interviews in the first wave. For almost half of them (5308) information for all three waves was available. ${ }^{4}$ We confined our analysis to those pupils which resulted in a strongly balanced panel. Moreover, all our models only included pupils with valid information for all the independent and dependent variables $(N=3566)$.

\subsection{Data Collection and Questionnaire Content}

The pupils were interviewed within a period of 45 min by means of a questionnaire on a tablet PC (offline classroom survey). In all the classes, a trained interviewer was present to introduce the questionnaire, to explain the workings of the tablet PC and to respond to questions from pupils. In the first part of the questionnaire, the children were interviewed about injuries in depth. Subsequently, the children's exercise routine and nutritional behaviour as well as their physical and mental health were assessed. In addition to the sociodemographic data, information about the context of the school was also collected, such as the information on the perceived state of the school building. Finally, the data set was enriched with further structural features of the participating schools (e.g. school stream, federal state).

\footnotetext{
${ }^{2}$ Secondary schools in Germany (grade 5 to 12 ) are basically stratified into two different academic categories. The lower stream aims to train young people for vocational education, whereas the upper stream ('Gymnasium') is oriented towards an academic education (to enter Universities).

${ }^{3}$ The survey could not be carried out in the federal states of Hamburg and Bavaria, as the political bodies (ministries) did not consent to the study. Nevertheless, 14 out of 16 federal states in Germany were a part of the survey. For pragmatic reasons, some of the East-German federal states entered the survey just in the wave three of 2016-17. This was due to the fact that in these federal states the primary school lasts for six instead of four years.

${ }^{4}$ Although panel mortality fortunately was quite low on the school level, we 'lost' half of the pupils between waves 1 and 3, mainly for three reasons: first, some parents did not consent in every wave to survey their children. Second, some pupils were not at school on the actual day when the survey was conducted - either because of illness or because they left that particular school (e.g. the family moved away). Finally, some pupils could not be re-identified since we had to rely on self-generated codes for matching our respondents.
} 


\section{Variables and Data Analysis}

\subsection{Independent Variables}

\subsubsection{Measuring the Social Capital in Children}

As argued earlier, generalized trust is a key aspect of social capital. We regard the following components of social capital as fields, in which children built up generalized trust in toto. In childhood and adolescence, one (hopefully) gains trust and support from one's parents. Hence, the quality of the parent-child relationship is of great importance. The second component that plays a pivotal role in child development is the school, as it is the institution where young people spend the most time of their day and experience important socialisation impulses. Therefore, the quality of schools is addressed by relying on the perceived relationships with other pupils (mutual trust). A third component of generalized trust is the quality of the immediate neighbourhood, as it concerns security or strangeness. 5

The scale indicators for all these three components were selected to achieve a sufficiently high degree of reliability (Cronbach's Alpha), while confining the number of items to be well applicable in the practical social research. The values of the indicators were transformed so that the higher values reflect a high volume of social capital for the respective items/components. The sum of the values for each component ranges from 0 to 1 . After that, the sum of these components was calculated and divided by 3 , resulting in an index of the total volume of social capital ranging again from 0 to 1. For the ease of interpretation, this index was finally transformed to range from 0 to 100. Relying on that construction, the values for the index were calculated for every pupil and for all the three waves. Table 1 presents an overview of the index.

The parent-child relation forms the first component of social capital. In the questionnaire, the children were given the option to indicate how easy or difficult it is for them to deal with personal matters with trustworthy individuals. This study only considers the categories of father and mother. ${ }^{6}$ The answer category 'don't have or see this person' was added to the lowest category because we cannot expect any support if there is nobody present. The two indicators together had values for Cronbach's Alphas, ranging between 0.55 and 0.59 (depending on the wave), which was almost acceptable given that the scale only consists of two items.

The perception of the school climate recurs on three single items that represent the social relations between the pupils. The three school indicators show a range of Cronbach's Alpha between 0.67 and 0.73. The assessment of the quality of the neighbourhood also consists of three indicators. These indicators have reliability values ranging from 0.69 to 0.75 in the three waves. The Cronbach's Alpha for the aggregate index of social capital ranges from 0.68 (wave 1) to 0.70 (wave 3). Thus, the index seems applicable for further analyses. Figure 1 presents an overview of the Social

\footnotetext{
${ }^{5}$ It is certainly possible to identify the other areas of life (for example, sport/leisure activities etc.), which may be of concern here. In a certain way, the conceptual framework could be sprawled.

${ }^{6}$ If no biological father or mother were present, the information of stepfather or stepmother was imputed if applicable.
} 
Table 1 Indicators of the social capital index

\begin{tabular}{llll}
\hline Dimension & Indicator & Response Categories & Scaling \\
\hline $\begin{array}{l}\text { Quality of relationship } \\
\text { to parents }\end{array}$ & $\begin{array}{c}\text { How easy is it for you to talk to the following persons about things that } \\
\text { really bother you? } \\
\text { Father or Stepfather } \\
\text { (if father is not present at home) }\end{array}$ & very easy & 0.5 \\
& easy & 0.375 \\
& difficult & 0.25 \\
Mother or Stepmother & very difficult & 0.125 \\
(if mother is not present at home) & don't have or see this person & 0 \\
& very easy & 0.5 \\
& easy & 0.375 \\
& difficult & 0.25
\end{tabular}

Quality of school climate
Here are statements about students at your school. Please tick to what extent you agree or disagree with the statements.

Most students in my class like being together

$\begin{array}{ll}\text { exactly true } & 0.33 \\ \text { is quite right } & 0.25 \\ \text { neither/nor } & 0.17 \\ \text { is not true } & 0.08 \\ \text { is not true at all } & 0 \\ \text { exactly true } & 0.33 \\ \text { is quite right } & 0.25 \\ \text { neither/nor } & 0.17 \\ \text { is not true } & 0.08 \\ \text { is not true at all } & 0 \\ \text { exactly true } & 0.33 \\ \text { is quite right } & 0.25 \\ \text { neither/nor } & 0.17 \\ \text { is not true } & 0.08 \\ \text { is not true at all } & 0\end{array}$

Most of the students in my class are kind and helpful

Other students accept me as I am

\section{Quality of neighbourhood}

Here are statements about your neighbourhood. Please tick to what extent you agree or disagree with the statements.

People greet each other and speak to each other

Smaller children can play outside during the day

One can trust people

$\begin{array}{ll}\text { exactly true } & 0.33 \\ \text { is quite right } & 0.25 \\ \text { neither/nor } & 0.17 \\ \text { is not true } & 0.08 \\ \text { is not true at all } & 0 \\ \text { exactly true } & 0.33 \\ \text { is quite right } & 0.25 \\ \text { neither/nor } & 0.17 \\ \text { is not true } & 0.08 \\ \text { is not true at all } & 0 \\ \text { exactly true } & 0.33\end{array}$


Table 1 (continued)

\begin{tabular}{llll}
\hline Dimension & Indicator & Response Categories & Scaling \\
\hline & is quite right & 0.25 \\
& neither/nor & 0.17 \\
& is not true & 0.08 \\
\hline
\end{tabular}

The numbers in the extreme right column refer to the scores that we ascribed for the answering options to obtain a range from 0 to 1 for each component of social capital

Capital Index. Over the three waves, the social capital index has a normal distribution with its mean and mode at 75 points and a slightly higher median (76).

\subsubsection{The Family Affluence Scale}

To analyse the influence of social background on health and health development, we included a measure of the socio-economic situation of the household that the children live in. If the social position of school children is to be captured, it can only be done with a proxy measurement, where the social position of the parents is considered. Parents were not interviewed in this survey and interviewing children in this age-group about their parents' income is not supposed to produce reliable results; thus, the measurement of the social position is carried out with comparatively simple, but robust indicators: The Family Affluence Scale (FAS) items developed by the international HBSC study group (Currie et al. 2012) are basically employed for this purpose. The
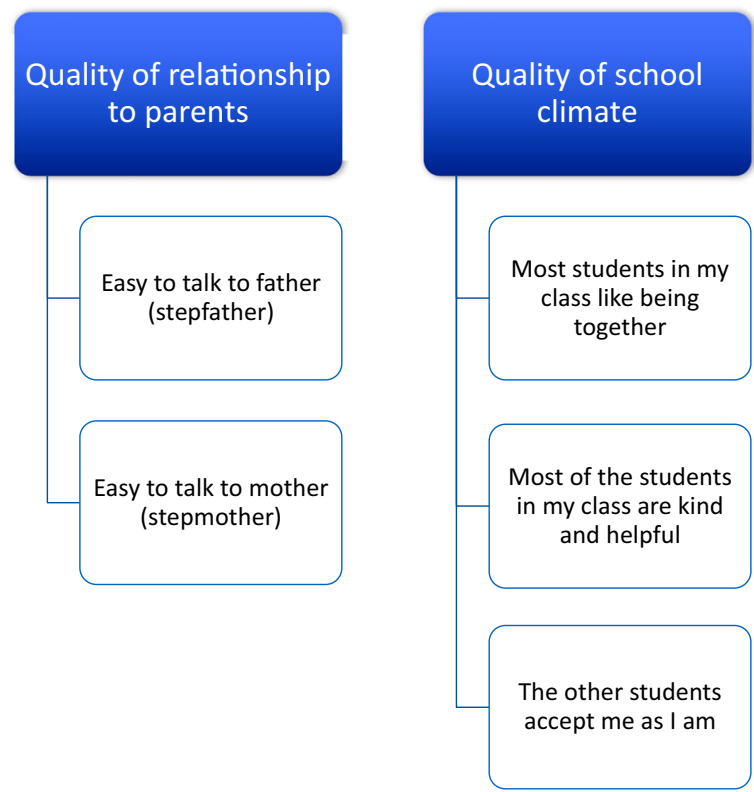

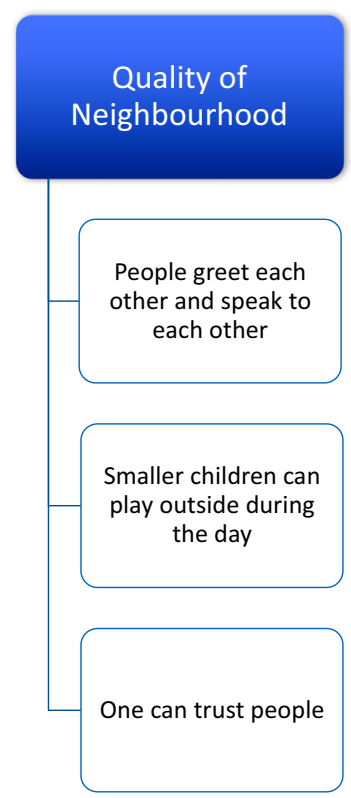

Fig. 1 An index of social capital in children 
index used here consists of the three original FAS items and an additional question, which taps the number of books in the household (see Table 2). In addition to the more 'materialistically' oriented items, the number of books in a household may also serve as a proxy indicating the parents' formal education.

All the four items used to measure family affluence were recorded to range from 0 to 0.25 , with higher values indicating higher affluence. Afterwards, the values of these items were summed up, and the final index was also recoded to range from 0 to 100 .

\subsubsection{Further Independent Variables}

Since we focus on the distribution of social capital within sociodemographic groups, we included the factors of gender $(0=$ boys, $1=$ girls $)$, migration $(0=$ both parents were born in Germany; $1=$ at least one parent was not), region $(0=$ west, $1=$ east $)$ and the type of school attended $(0=$ intermediate and lower stream, $1=$ higher stream) as controls.

\subsection{Dependent Variables}

We confined ourselves to six health-related variables that cover the general health status, mental health and health behaviour. For measuring the pupils' health status, they self-assessed their general health status on a five-point-scale, ranging from 'very poor', 'poor', 'fair', 'good' to 'excellent'. Furthermore, we asked the pupils how often in the last week (a) they had difficulties in getting to sleep, (b) they could not concentrate well and (c) they felt fit and comfortable, using a five-point scale ranging from 'not at all',

Table 2 Indicators of the family affluence scale

\begin{tabular}{|c|c|c|}
\hline Indicator & Response Categories & Scaling \\
\hline \multirow[t]{3}{*}{ Does your family own a car? } & no & 0 \\
\hline & yes, one & 0.125 \\
\hline & yes, two or more & 0.25 \\
\hline \multirow{4}{*}{$\begin{array}{l}\text { During the past } 12 \text { months, how many times did you } \\
\text { travel on holiday with your family? }\end{array}$} & not at all & 0 \\
\hline & once & 0.08 \\
\hline & twice & 0.17 \\
\hline & more than twice & 0.25 \\
\hline \multirow[t]{2}{*}{ Do you have a bedroom for yourself? } & no & 0 \\
\hline & yes & 0.25 \\
\hline \multirow{5}{*}{$\begin{array}{l}\text { How many books do you have at home? Please do } \\
\text { not include magazines, newspapers or textbooks! }\end{array}$} & none or very few $(0-10$ books $)$ & 0 \\
\hline & about a bookshelf (11-25 books) & 0.06 \\
\hline & about a shelf (26-100 books) & 0.13 \\
\hline & about two shelves (101-200 books) & 0.19 \\
\hline & three or more shelves (more than 200 books) & 0.25 \\
\hline
\end{tabular}

The numbers in the extreme right column refer to the scores ascribed for the answering options to obtain a range from 0 to 1 for the FAS 
'one day per week', '2-4 days per week', '5-6 days per week' to 'every day'. Finally, we asked how often during the week before the interview the pupils drank 'Coke or lemonade', and how often they ate 'vegetables and salad', using the same five-pointscale as stated before. For the ease of interpretation, we treated all these variables as a metric and recoded them to range from 0 to 4 for the variable comprising general health status, and from 0 to 7 for those variables representing mental health and health behaviour. ${ }^{7}$ All other variables were integrated into the models on their original scale.

\subsection{Strategy of Analysis}

The analysis consists of the following three parts: first, social capital was regarded as the dependent variable and its distribution is analysed in distinguished sociodemographic groups. Since we dealt with repeated measurements from pupils clustered in schools, we estimated a multilevel model with observations at level 1, the pupils at level 2 and the schools at level 3. This model not only accounts for the clustering in the data but also for its panel structure (Rabe-Hesketh and Skrondal 2008). We additionally added the wave as a predictor to capture the lifecycle-effects.

In the second part, we shifted the focus and regarded social capital as an independent variable. Here, we estimated its effects on our six dependent variables alongside family affluence and the other predictors. Again, multilevel models were used to account for the clustering and the panel structure. In the third and central part of the analysis, we made full use of our longitudinal data by estimating the impact of changes in the volume of social capital and family affluence on the health-related variables, relying on fixed effect models. This approach is best suited for testing causal relationships using non-experimental data (Allison 2009). Finally, we analysed the effect of changes in social capital's volume in certain socio-demographic groups by integrating interaction terms.

\section{Findings}

We start our analysis by estimating the distribution of social capital's volume in certain socio-demographic groups. In Table 3, two three-level models are displayed: The first one represents the null model that simply reflects the grand mean of social capital's volume. Apart from that, the null model also shows how the variance in the volume of social capital is distributed among the three levels. The model further reveals that the school-level (level 3) hardly plays any role since only $2.6 \%$ of the variance is located there. The residual variance is almost evenly distributed between the pupils $(49.3 \%)$, and the three measurements within the pupils $(48.1 \%)$. This suggests a high amount of inter- as well as intra-personal variance of social capital. The fact that social capital varies within the pupils over time is important given that fixed-effects models only work properly if the variable of interest shows a certain degree of variability. Those models will be employed in the final step of our analysis.

\footnotetext{
$\overline{{ }^{7} \text { not at all }=0 ; \text { one day per week }}=1 ; 2-4$ days per week $=3 ; 5-6$ days per week $=5.5$; every day $=7$
} 
Table 3 The distribution of social capital in a multilevel perspective

\begin{tabular}{|c|c|c|c|c|c|c|}
\hline & \multicolumn{3}{|l|}{ null model } & \multicolumn{3}{|l|}{ full model } \\
\hline & $\mathrm{b}$ & se & $\mathrm{p}$ & $\mathrm{b}$ & se & $\mathrm{p}$ \\
\hline \multicolumn{7}{|l|}{ Individual characteristics } \\
\hline Family Affluence (FAS) & & & & .119 & .009 & $* * *$ \\
\hline Gender (Girl) & & & & -.693 & .359 & \\
\hline Migrant background & & & & -.708 & .427 & \\
\hline \multicolumn{7}{|l|}{ School characteristics } \\
\hline Region (Eastern Germany) & & & & -2.56 & .801 & $* *$ \\
\hline School stream (high) & & & & 1.20 & .497 & $*$ \\
\hline \multicolumn{7}{|l|}{ Panel waves (W3 = ref) } \\
\hline Wave 1 & & & & 5.17 & .211 & $* * *$ \\
\hline Wave 2 & & & & 2.01 & .210 & $* * *$ \\
\hline Constant & 76.07 & .280 & $* * *$ & 64.66 & .815 & $* * *$ \\
\hline \multicolumn{7}{|l|}{ Random effects } \\
\hline Level 1-Var (Observations) & 85.42 & 1.43 & & 78.74 & 1.32 & \\
\hline Proportion of Var. & $48.1 \%$ & & & $47.3 \%$ & & \\
\hline Reduction of Var. (full vs. null) & & & & $7.8 \%$ & & \\
\hline Level 2-Var (Pupils) & 87.44 & 2.83 & & 85.59 & 2.73 & \\
\hline Proportion of Var. & $49.3 \%$ & & & $51.3 \%$ & & \\
\hline Reduction of Var. (full vs. null) & & & & $2.1 \%$ & & \\
\hline Level 3-Var (Schools) & 4.55 & 1.23 & & 2.37 & .865 & \\
\hline Proportion of Var. & $2.6 \%$ & & & $1.4 \%$ & & \\
\hline Reduction of Var. (full vs. null) & & & & $47.9 \%$ & & \\
\hline Log likelihood & $-41,516.14$ & & & $-41,146.26$ & & \\
\hline \multicolumn{7}{|l|}{$\mathrm{N}$} \\
\hline Level 1 (Observations) & 10,698 & & & & & \\
\hline Level 2 (Pupils) & 3,566 & & & & & \\
\hline Level 3 (Schools) & 121 & & & & & \\
\hline
\end{tabular}

$* p<0,05 * * \mathrm{p}<0,01 * * * \mathrm{p}<0,001$

The second model in Table 3 includes independent variables on the school and individual level. Here, it becomes obvious that the FAS is positively related to social capital's volume. ${ }^{8}$ On the school level, pupils visiting schools from the highest stream and from the Western part of Germany showed a higher volume of social capital. Finally, those variables representing the different waves suggested that the volume of social capital is declining over time, since the coefficient is highest for wave 1 and still significantly higher in wave 2 than for the reference group (measurements at wave 3 ). While on the school level, almost half of the (small) share of variance can be explained

\footnotetext{
${ }^{8}$ To illustrate its impact on the dependent variable, we calculated the difference in the (estimated) volume of social capital for pupils with the lowest and highest FAS (25 vs. 100). This difference amounts almost 9 points, meaning that its impact is greatest among all independent variables in the full model.
} 
by integrating school streaming and region, only $2.1 \%$ of the variance on the individual level can be attributed to the predictors. This reflects that the volume of social capital can hardly be explained by socio-demographic variables.

The second part of our analysis estimated the impact of social capital on the six health related variables in distinct multivariate, multilevel models. Table 4 reveals that a higher amount of social capital goes along with a better health status, and with more days in which pupils feel fit and comfortable and eat vegetables and salad. Contrastingly, the higher the volume of social capital the lesser sleep difficulties, problems to concentrate and consumption of coke or lemonade were reported by the pupils. Except from drinking coke or lemonade, social capital always outperforms the influence of family affluence. Generally, the volume of social capital is highly linked with health status, mental health and health behaviour while its effect is largest for the different features of mental health (sleep difficulties, problems to concentrate, feeling fit and comfortable) and smallest for health behaviour (drinking coke or lemonade, eating vegetables and salad). Moreover, social capital largely contributes to the reduction of variance on the pupils' level, which overall varies between 5 and 33\%. Estimating stepwise models showed that social capital always accounts for the largest share of this explained variance.

By now, we have shown: (i) children's volume of social capital is almost evenly distributed in certain socio-demographic groups and (ii) social capital has a large effect on the health and health behaviour of young people, which is independent from the socio-economic position of their families. In the final step, we analysed whether our longitudinal data uncovers hints for a causal effect of social capital on the health and health behaviour of the surveyed pupils. For that, we estimated fixed effects models in which (individual) changes in the health-related variables between the waves served as the dependent variables. On the other hand, changes in the volume of social capital is the key independent variable. Apart from that, we integrated a variable in each model indicating the different panel waves. This is necessary to include information of those pupils, whose volume of social capital did not change between the panel waves (the 'control group') and to account for period and/or age effects (Brüderl 2010). Fixed effects models do not allow to estimate the effects of pupils' characteristics that do not change over time (e.g., sex, migrant background). In the logic of the within-estimator, this is straightforward because those attributes cannot contribute anything to the causal effect on the dependent variable. However, time-invariant characteristics may be integrated in fixed-effects models as interaction terms to test whether the effect of changes in the independent variable is different for certain subgroups (Wooldridge 2010). We integrated such interaction terms in our models to test whether the effect of changes of the volume of social capital on the health-related variables is equal for pupils with and without a migrant background, and for pupils who live in an affluent household and those who do not. In other words, we wanted to figure out if an increase in the volume of social capital goes along with a better health status and health behaviour of our surveyed pupils - and if so, whether this effect holds true for all the pupils, independent of their social position. We used the grand median to create a group with a high and a low family affluence. ${ }^{9}$

\footnotetext{
${ }^{9}$ If a pupil showed an above median family affluence in one wave and a below family affluence in the other two waves (or vice versa), he/she was assigned to the group with a low (high) FAS.
} 


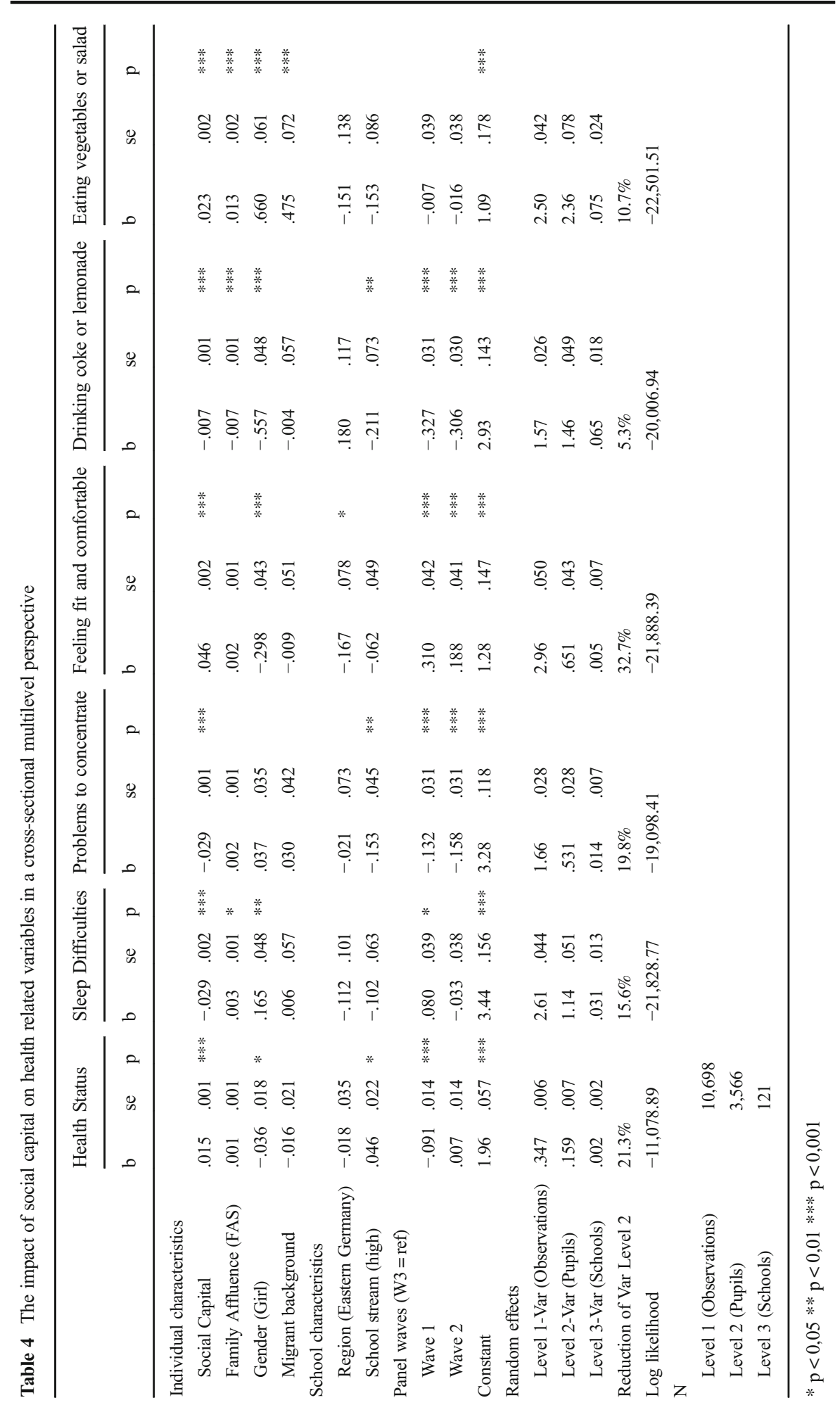


In sum, the models in Table 5 offer strong evidence for a causal effect of social capital on the health-related variables. An increase in the volume of social capital by one unit triggers, for example, an increase of .035 days per week in which the pupils feel fit and comfortable. To get an impression about how substantive this effect is, a closer look at the aggregate variability of the volume of social capital between the different panel waves was taken. When we calculate the differences in the volume of social capital between wave 1 and 2, and between wave 2 and 3 for each individual, the standard deviation of these variables is 12. Although formally incorrect, this value indicates the mean variability (as an absolute value) in the volume of social capital between the waves. In other words, an increase in the volume of social capital by that mean variability would result in an increase of almost half a day per week $(12 * .035=.42)$ in which the pupils feel fit and comfortable. On the other hand, such an increase in the amount of social capital results in a decrease of more than 0.2 days per week in which pupils had problems in concentrating, and in 0.1 days per week in which the pupils suffered from sleep difficulties. Finally, an increase of social capital leads to more days in which pupils eat vegetables and salad, and, in general, to a better health status.

The interaction terms in the models reveal no evidence that pupils come from a financially well-established family or whose parents were both born in Germany benefit most from an increase in the volume of social capital. Rather, pupils benefitted from an increase in social capital regardless of their family affluence and migrant background. Further analyses also showed that all three components of social capital (see Fig. 1) contribute to a better health status, mental health and health behaviour in a similar way. In other words, there is no single component that predominates the dependent variables.

\section{Discussion}

This study indicates that social capital is a powerful tool in the analysis of health and health behaviour in childhood. This is especially true when young people are in the process of growing up. This study's findings demonstrated that an intrapersonal change in social capital over time has a significant effect on the health and health behaviour of an individual. Hence, it can be interpreted as a causal factor affecting the health development in young age. This is true as the fixed effects models 'fix' all the individual invariant characteristics (i.e. age, sex), so the observed change in the outcome-variable can be assigned to the change in the central independent variable. This is what we wanted to analyse in this study. Despite the numerous cross-sectional studies concerning the effectiveness of social capital, longitudinal panel data is quite rare. Runyan et al. (1998) found that in longitudinal data, social capital improved the health outcomes of deprived children, but this finding was from a small sample of children aged between 4 and 8 years coming from deprived settings. The research study teams of Snelgrove et al. (2009), and Sessions et al. (2011) as well as other teams confirmed a positive effect of social capital on health in adults, analysing the British Household Panel. Islam et al. (2006) concluded from a literature review that an association between the social capital and health at the individual (adult) level was robust with respect 


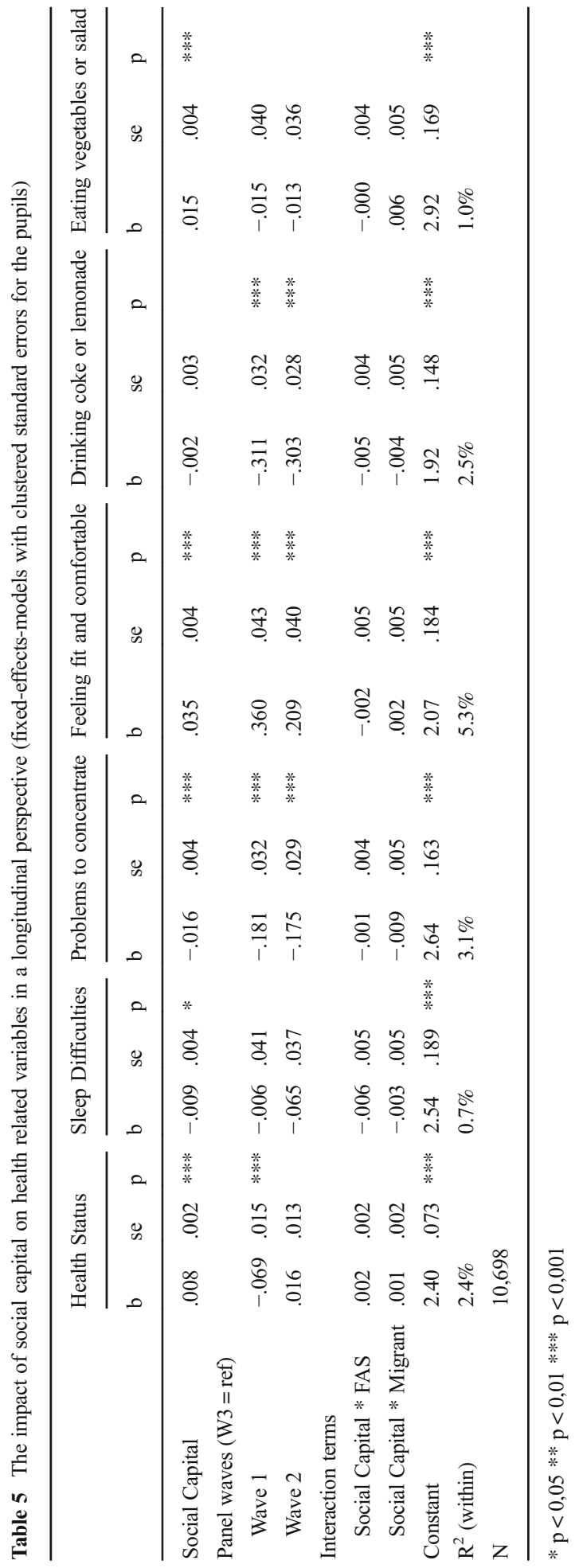


to the degree of egalitarianism in a country. Regarding children, longitudinal data is still rare (Halpern 2005). Here we would like to see our findings.

The concept of social capital itself is largely independent of the sociodemographic features, such as socioeconomic position (FAS here), migration, gender or region. This is an important quality, which underpins the concept's independence. It is not just a proxy for something else, but has power in its own right, which establishes its role as a sociological concept. It is also applicable to younger age groups. Social capital of an individual, as conceptualised here, did work as an empirical tool and in a longitudinal design. This strengthens the theoretical conception of social capital as an individualistic concept, as it is put forward by Lin (2001) as well as Coleman (1990) and Bourdieu (1986).

From our initial hypothesis, we have mixed results. Hypothesis 1 stated a significant effect of social capital on health and health behaviour in young people, which was supported. Here, social capital had a clear impact on the health status and the well-being (mental health) of children. The health behaviour, on the other hand, was less clearly shaped by social capital, whereas the socioeconomic position of the family (FAS) worked in the other way. FAS has an impact on the health behaviour, but no significant effect on the health status. This might be an effect of socially stratified family habits (captured with FAS) on the child's health behaviour (here: nutrition). The health status, especially mental health, on the other hand, is much more depended on connectedness to and in mutual social networks and ties, e.g. social capital. Here we see support for the conceptional idea of social capital. The second hypothesis stated that children, who gain a higher volume of social capital over time, will show a significant better health was impressively verified. This indicated that social capital has a causal effect on the health development in childhood. That's what we wanted to demonstrate in this paper. Finally, all the components of social capital work in the same positive direction to a better health, which holds true for all the sociodemographic groups (hypothesis 3). Thus, to transform the empirical facts into political consequences, we would like to argue that for the health development of children and adolescents, it is of foremost importance to build and stimulate social networks and resources (social capital) rather than concentrating solely on the financial aid.

\section{Limitations}

The analyses undertaken in this study has several limitations. The concept of social capital itself is questionable. There are other domains, which can be regarded as a constitutive for this concept. However, surveying several domains is impractical for the school-based surveys. We relied on self-reported dependent variables, which might have a response bias. Class-based surveys are also prone to influence from others. Furthermore, the findings might be limited as the children were surveyed on an annual basis, and there is a possibility of missing the changes in social capital or health during comparably long survey intervals. There is also quite a lot of missing data due to panel attrition and missing linkage of cases. 
Funding The panel study 'Health Behaviour and Injuries during School Age' is funded by the 'Deutsche Gesetzliche Unfallversicherung’ (DGUV).

Open Access This article is distributed under the terms of the Creative Commons Attribution 4.0 International License (http://creativecommons.org/licenses/by/4.0/), which permits unrestricted use, distribution, and reproduction in any medium, provided you give appropriate credit to the original author(s) and the source, provide a link to the Creative Commons license, and indicate if changes were made.

\section{References}

Allison, P. (2009). Fixed effects regression models. Thousand Oaks: SAGE.

Bourdieu, P. (1986). The forms of capital. In J. Richardson (Ed.), Handbook of theory and research for the sociology of education (pp. 241-258). New York: Greenwood.

Bronfenbrenner, U. (1979). The ecology of human development. Harvard: Harvard University Press.

Brüderl, J. (2010). Kausalanalyse mit Paneldaten. In C. Wolf \& H. Best (Eds.), Handbuch der sozialwissenschaftlichen Datenanalyse (pp. 963-994). Wiesbaden: VS Verlag.

Chzhen, Y., Bruckauf, Z., Toczydlowska, E., et al. (2017). Multidimensional poverty among adolescents in 38 countries: Evidence from the health behaviour in school-aged children (HBSC) 2013/14 study. Child Ind Res. https://doi.org/10.1007/s12187-017-9489-0 .

Coleman, J. S. (1990). Foundations of social theory. Cambridge: Harvard University Press.

Currie, C., Zanotti, C., Morgan, A., Currie, D., de Looze, M., Roberts, C., et al. (Eds.). (2012). Social determinants of health and well-being among young people. Health behaviour in school-aged children (HBSC) study: International report from the 2009/2010 survey. Copenhagen: WHO Regional Office for Europe.

Field, J. (2017). Social Capital. London: Routledge.

Furstenberg Jr., F. F., Cook, T. D., Eccles, J., Elder Jr., G. H., \& Sameroff, A. (1999). Managing to make it. Chicago: University of Chicago Press.

Giddens, A. (1990). The consequences of modernity. Stanford: Stanford University Press.

Halpern, D. (2005). Social capital. Cambridge: Polity Press.

Helliwell, J., Layard, R., \& Sachs, J. (2017). World happiness report 2017. New York: Sustainable Development Solutions Network.

Islam, K. M., Mero, J., Kawachi, I., Lindström, M., \& Gerdtham, U. G. (2006). Social capital and health: Does egalitarianism matter? A literature review. International Journal for Equity in Health, 5(3).

Klocke, A., Clair, A., \& Bradshaw, J. (2014). International variation in child subjective well-being. Child Indicators Research, 7(1), 1-20.

Lin, N. (2001). Social capital: A theory of social structure and action. Cambridge: Cambridge University Press.

Morrow, V. (1999). Conceptualising social capital in relation to the well-being of children and young people: A critical review. The Sociological Review, 47, 744-765.

Putnam, R. D. (1995). Bowling alone: America's declining social capital. Journal of Democracy, 6, 65-78.

Putnam, R. D. (2001) (Ed.). Gesellschaft und Gemeinsinn. Gütersloh: Verlag Bertelsmann Stiftung.

Putnam, R. D. (2015). Our kids: The American dream in crisis. New York: Simon \& Schuster.

Rabe-Hesketh, S., \& Skrondal, A. (2008). Multilevel and longitudinal modeling using stata (2nd ed.). College Station: Stata Press.

Runyan, D., Hunter, W., \& Socolar, R. (1998). Children who prosper in unfavourable environments: The relationship to social capital. Pediatrics, 101, 12-18.

Sessions, J., Yu, G., \& Wall, M. (2011). Social capital and health: A longitudinal analysis from the British household panel survey, Working Paper. Bath: Department of Economics, University of Bath (Bath Economics Research Papers No. 6/11).

Snelgrove, J., Pikhart, H., \& Stafford, M. (2009). A multilevel analysis of social capital and self-rated health: Evidence from the British household panel. Social Science \& Medicine, 68(11), 1993-2001.

UNICEF Office of Research. (2016). Fairness for children: A league table of inequality in child well-being in rich countries, Innocenti report card 13. Florence: UNICEF Office of Research - Innocenti.

United Nations Development Programme (UNDP) (2016). Human Development Report 2016: Human Development for Everyone. http://hdr.undp.org/sites/default/files/2016_human_development_report.pdf. Accessed on 13 October 2017. 
Uslaner, E. M. (2002). The moral foundations of trust. Cambridge: Cambridge University Press.

Veenhoven, R. (2008). Sociological theories of subjective well-being. In M. Eid \& R. J. Larsen (Eds.), The science of subjective well-being (pp. 44-61). New York: Guilford Press.

Woolcock, M. (2001). The place of social capital in understanding. Social and economic outcomes. Retrieved from http://www.oecd.org/innovation/research/1824913.pdf. Accessed on 13 October 2017.

Wooldridge, J. (2010). Econometric analysis of cross section and panel data (2nd ed.). Cambridge: MIT Press. 